\title{
Health economics in mental health. 1: Principles
}

\author{
Neil Craig and Cameron Stark
}

This is the first of two papers which summarise key concepts in health economics and explains the differences in the various types of economic evaluation published in the economics literature. Examples from the economic analysis of mental health care are used to illustrate the key points. This paper explains the concepts of scarclty, rationing, opportunity cost and efficiency from a health economics perspective, and presents an ethical argument for the use of health economics in making decisions on resource use in mental heatth care.

There is currently a strong emphasis upon health economics within the National Health Service (NHS) (Mooney, 1991; Drummond \& Maynard, 1993) and use is being made of a growing body of published work. Many health authorities and health boards (commissioners in the remainder of this series of papers) now employ health economists or have links to economists in academic units. Clinicians can therefore expect to see more economic analyses carried out locally and more use made of the results of economic analysis by local commissioners.

Much of the work of health economists has been directed towards acute medical and surgical services, but the policy emphasis currently being placed on community care and general mental health issues has encouraged researchers and commissioners to examine the economics of mental health services (Knapp, 1995).

Many clinicians will consider health economics to be either abstruse or unethical. As the use of health economics by health care commissioners grows, service providers will have to understand and respond to economic analyses. This series of papers aims, first, to summarise key concepts in health economics, paying particular attention to their application to mental health care, and second, to discuss types of economic analyses and their strengths and weaknesses.

\section{Key concepts in health economics Scarcity}

Economic theory assumes that where goods and services are free to the consumer, demand is limitless, while resources with which to meet these demands are finite. Although this does not necessarily hold for some conditions where there is an identifiable and finite pool of need, scarcity of resources is relevant to specialist mental health services because of the pyramid of psychological morbidity described by Goldberg \& Huxley (1980). Mental health services deal with a very small proportion of all depressed patients. The remainder are either not identified. or they are treated in primary care (Goldberg \& Huxley, 1980). A shift of these individuals to specialist mental health teams would swamp services. Although demand may not be infinite, it is likely that need and demand will continue to exceed supply of specialist services. In this sense, resources are scarce.

\section{Rationing}

The consequence of scarcity is that some degree of rationing is inevitable. Rationing is a process of priority setting, of making choices between courses of action and different kinds of health service. The need to choose is a direct result of scarcity. The allocation of additional resources to the NHS would make some of the choices that commissioners and practitioners currently have to make less stark, but it would not obviate the need to choose.

Rationing is a concept which causes many clinical workers pause. There is, however, already rationing in mental health, with general practitioners (GPs) acting as gatekeepers to services and the services themselves limiting their activity to certain types or categories of patients. Those who are unsuitable or who do not require continuing specialist care are referred back to GPs or to other types of service, limiting specialist mental health services to those whom practitioners feel will most benefit.

\section{Opportunity costs}

The choices required in setting priorities involve sacrifices in the form of the benefits that would have been generated had some other service been provided using the same resources. Ideally 
these sacrifices should be minimised by investing resources in the services which maximise health or, more broadly, well-being. The information required to move towards this ideal is the relationship between the costs and outcomes of different health services. It is this relationship that economists call efficiency.

Sacrifice is involved irrespective of whether the resources required to provide a particular service have a financial cost. For example, the opportunity cost of time spent by carers on looking after patients is the benefit that would have arisen had that time been put to other uses, such as employment or leisure. The opportunity cost of voluntary sector services used to support patients and carers in the community is the benefit that would arise if voluntary services were put to different uses because patients were kept in hospital. The opportunity cost of land or buildings currently used to provide mental health care is the benefit that would have been generated by alternative forms of care that could have been provided in other specialities using the same resources.

The key point is that although the use of such resources does not involve a financial transaction, they have an opportunity cost, that is, the benefit the resources would generate in their best alternative use. Financial (or accounting) costs give a partial picture of the opportunity cost which represents the true economic cost of the resources used to provide a particular service.

\section{Technical and allocative efficiency}

Scarcity and rationing therefore require choices to be made which, to maximise the welfare of the population as a whole, should include consideration of efficiency. Decision-makers face different kinds of choices which require more specific definitions of efficiency. For example, decisionmakers may face a decision to treat patients with depression either with drugs or with cognitive therapy. This is a question of technical efficiency, the most efficient way of achieving a given objective, in this case the relief of depression. A measure of technical efficiency would be the respective cost per patient whose depression is relieved for the two-treatment models.

Decision-makers also need to choose between services with different objectives such as services for psychosexual dysfunction or adolescent psychiatry services. This is a question of allocative efficiency, the relationship between costs and overall benefits, where benefits may relate to a range of objectives and where the objectives of the services being compared may differ. Benefits are broadly defined in terms, for example, of improvements in patients' health net of any sideeffects, relief of strain on carers, or gains to society in terms of reduced time off work. Allocative efficiency therefore relates to the broader question of whether treatments are worthwhile per se, in contrast to technical efficiency which relates to the cost-effectiveness of different methods for achieving a given objective.

\section{Ethics}

Practitioners often express concern that economic analyses focus on money to the detriment of service quality or patient benefit. This concern reflects the misconception that economic analyses refer only to financial costs. Some of the unease service providers feel is related to the possibility that an existing service will be scaled down or withdrawn as the result of a financial analysis which takes no account of broader economic costs in relation to benefits.

Such concerns should not discourage the use of, or search for, health economic analyses to inform decisions for two reasons. First, in practice, such decisions inevitably take into account local sensitivities, professional and consumer views and the likely impact on other services alongside financial and economic analyses. Second, there is a compelling moral argument for economic analysis of the efficiency implications of different service choices. Choices involve sacrifices or opportunity costs. The existing pattern of health services involves opportunity costs. The question for service providers and commissioners is whether these costs are greater or lesser than the sacrifices involved in putting resources to different uses, or from choosing to invest additional resources in a particular way. This is a question of efficiency. Continuing with services as they currently exist is an example of implicit decision-making, where resources are denied to others with no discussion of the possible opportunity costs. The advantage of the explicit decision-making associated with economic analyses is that the decision can be held up to scrutiny. Leaving a service as it has developed through historical circumstances simply because it already exists denies this opportunity.

\section{Conclusion}

More use is being made of health economics in the planning and delivery of health services. The volume and quality of analyses of mental health and community care services is increasing. For service providers to enter into discussions with health care commissioners in which economic analyses are part of the information being considered, it is important that they are familiar with the language used, can comment on the 
appropriateness of the type of analysis undertaken, and are able to assess the strengths and weaknesses of the particular study. These issues are considered in the second paper in this series.

\section{References}

DRUMmond, M. \& MAYNARD, A. (1993) Purchasing and Providing Cost-Effective Health Care. Edinburgh: Churchill Livingstone.

GolDBERG, D. \& HuXLEY, P. (1980) Mental Illness in the Community: The Pathway to Psychiatric Care. London: Tavistock.
KNAPP, M. (ed.) (1995) The Economic Evaluation of Mental Health Care. Aldershot: Arena.

MOONEY, G. H. (1991) Economics, Medicine and Health Care. Brighton: Wheatsheaf Books.

*Neil Craig. Health Economist, Department of Public Health, University of Glasgow, 2 Lilybank Gardens, Glasgow G12 8RZ; and Cameron Stark, Consultant in Public Health Medictne, Highland Health Board, Beechwood Park, Inverness IV2 3HG

*Correspondence

\title{
Psychiatric Aspects of Physical Disease
}

\author{
Edited by Allan House, Richard Mayou \& Christopher Mallinson
}

This book describes the extent and nature of psychiatric problems associated with physical illness and the ways in which both can be managed by physicians and psychiatrists. Examples are given of simple measures that can be incorporated into routine care and of occasions where specialist referral is appropriate. The book comprises edited papers based on a joint conference of the Royal Colleges of Physicians and Psychiatrists together with additional editorial sections. It provides a sister volume to Medical Symptoms not Explained by Organic Disease and complements the joint report of the two Colleges on Psychological Care of Medical Patients: Recognition of Need and Service Provision.

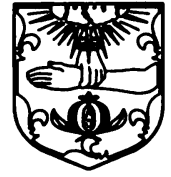

$\bullet £ 15.00 \bullet 110$ pp. $1995 \bullet$ ISBN 1873240929

Available from bookshops and from the Publications Department, Royal College of Psychiatrists, 17 Belgrave Square, London SW1X 8PG (Tel. 0171-235 2351, extension 146)

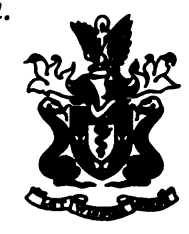

